\title{
La guerra como espectáculo mediático. La prensa centroamericana en la Gran Guerra (1917)
}

\author{
Patricia VegA JimÉneZ \\ Universidad de Costa Rica \\ patriciavega@racsa.co.cr
}

Recibido: 14 de julio de 2013

Aceptado: 17 de septiembre de 2013

\begin{abstract}
Resumen
La participación de los Estados Unidos en la Gran Guerra en el año de 1917, fue el resultado de múltiples factores, uno de ellos fue la presión que ejercieron los principales periódicos del mundo. La prensa centroamericana, particularmente la de Costa Rica y El Salvador no fue la excepción; influyeron echando mano de diversas estrategias, impulsando al Gobierno estadounidense para que tomase la decisión de participar en el conflicto que desangraba Europa.

En este estudio se analizan esas estrategias y el rol de la prensa centroamericana en el proceso.
\end{abstract}

Palabras clave: Prensa; guerra; Estados Unidos; estrategias periodísticas; Centroamérica.

The War as a Media Spectacle. The Central American Press in the Great War (1917)

\begin{abstract}
United States participation in the Great War of 1917 was the outcome of multiple factors, one of them was the pressure excerted by the main news papers around the world. Central American press, particulary from Costa Rica and El Salvador was not the exception; influenced the United States' government into deciding to participate in the conflict suffered by Europe by applying multiple strategies.

This study analyzes these strategies and the roll played by the Central American press during the process.
\end{abstract}

Key Words: Press; War; United States; Press strategies; Central Américan

\section{Referencia normalizada}

Vega Jiménez, P. (2013). La guerra como espectáculo mediático. La prensa centroamericana en la Gran Guerra (1917). Historia y Comunicación Social. Vol. 18, págs. 43-61.

Sumario:1. Introducción. 2. Las fuentes noticiosas y la manipulación informativa. 3. Los temas noticiosos. 4. La ruptura de relaciones de Estados Unidos con Alemania. 5. Las noticias sobre la declaratoria de Guerra. 6. Conclusión. 7. Bibliografía.

\section{Introducción}

La Primera Guerra Mundial significó un cambio decisivo en la forma de hacer periodismo en América Central. En los cuatro años que tardó el conflicto -19141918-, los encargados de los periódicos buscaron y ensayaron diversas maneras de presentar la noticia en pos de capturar lectores. Cambiaron los titulares no solo en 
su tamaño sino también en su aspecto, introdujeron el encabezado respondiendo a las cinco preguntas básicas que ya en los periódicos neoyorquinos se usaba con frecuencia desde hacía más de dos décadas, las imágenes, los mapas, los gráficos y los montajes, acompañaron las informaciones dándole una explicación visual adicional al texto (Vega, 2007, 2010).

Durante los iniciales meses del conflicto, la prensa dedicó el 100\% de sus páginas a detallar las batallas y los encuentros diplomáticos, pero durante el primer semestre de 1917, los esfuerzos periodísticos se abocaron a provocar y "forzar" el ingreso de los Estados Unidos en la contienda. Si bien es cierto desde el inicio tomaron posición a favor de la triple entente, en 1917 la actitud fue de un claro y abierto apoyo.

Se construyó la imagen de que la participación de los Estados Unidos era decisiva para que los aliados lograran el triunfo frente a los imperios centrales. Se presentó como la única nación capaz de conducir a la paz, a la libertad y a la democracia. Para lograr el apoyo de la potencia norteamericana, los periódicos insistieron en la necesidad de convencer al Presidente Thomas Woodrow Wilson y a las autoridades correspondientes, a tomar la decisión de responder a los ataques alemanes de los que, según la prensa, eran víctimas diariamente. ¿La prensa llama a Estados Unidos a la guerra o Estados Unidos manipula a la prensa para ingresar en el conflicto? El objetivo de este ensayo es dar respuesta a esta interrogante y analizar la intencionalidad manifiesta y subyacente de los principales periódicos de Costa Rica-La Información- y El Salvador -Diario Oficial de El Salvador-durante el primer semestre de 1917 cuando se define la participación abierta de Estados Unidos en la Primera Guerra Mundial.

Ambos periódicos tienen en común su vínculo con el poder ejecutivo de sus naciones de origen. La Información, aunque no es oficial, apoya abiertamente la gestión del General Federico Tinoco, entonces Presidente de la República. El Diario Oficial de El Salvador, es el medio a través del cual se informa sobre los movimientos poblacionales, la situación comercial, los acuerdos legislativos y ejecutivos pero además, mantiene una sección permanente de noticias internacionales. Hasta entonces, el Diario de El Salvador había ocupado el lugar de privilegio en esa República Centroamericana pero dejó de circular en 1917, razón por la cual se tomó como fuente, el Diario Oficial cuya circulación se mantuvo inalterada.

Durante los primeros seis meses del año 1917, El Diario Oficial de El Salvador publicó 1795 noticias mientras que La Información de Costa Rica difundió 669 informaciones, un promedio de 11,50 noticias diarias el primero y 4,28 el segundo.

La diagramación de los periódicos determinó la cuantía de noticias que se consideraron en este ensayo; por ejemplo, La Información agrupaba, bajo un titular y la misma columna, varias informaciones, separadas por un punto y seguido o aparte o, en el menor de los casos, por un subtítulo, lo que condujo a registrarlas como una sola nota, mientras que su homólogo salvadoreño detalla uno a uno los cables sin asignarles un titular, por tanto se contaron como noticias independientes. 
Se eligieron estos dos impresos porque son los de mayor circulación en ese momento en cada uno de los países, con cerca de 15000 ejemplares diarios cada uno. Se elige Costa Rica por ser el país donde opera la United Fruit Company (UFCO) que es la empresa dueña de las conexiones inalámbricas en Centroamérica y el Caribe y encargada de distribuir los cables de la Associated Press (AP), la principal agencia de noticias internacionales de la zona, y El Salvador porque es el único país de Centroamérica donde la UFCO no tiene subsidiarias y por tanto, podría favorecer el ingreso de otras agencias informativas además de la AP.

El análisis se delimita temporalmente de enero a junio de 1917 con el objetivo de realizar un estudio minucioso del primer semestre de ese año. Aunque las acciones de Estados Unidos y de la triple Entente para que la potencia americana participara abierta y decididamente en el conflicto que desgasta a Europa y que afecta ya a las colonias africanas, se llevan a cabo desde el inicio de la guerra, no será sino hasta este semestre cuando se acelerará el proceso, se rompen relaciones con Alemania y Austria y Estados Unidos declara formalmente la guerra a las potencias centrales.

La prensa, que jugó un papel fundamental en todo el proceso, asume a partir de enero de 1917, una actitud deliberada en función de presionar la presencia estadounidense a través de una campaña orquestada y de la manipulación informativa. Los principales periódicos centroamericanos, como los elegidos en este trabajo, también participan en la cruzada y el propósito es determinar la magnitud de su contribución y la manera como la intervención de la Estados Unidos en la guerra, afecta la forma de hacer periodismo.

\section{Las fuentes noticiosas y la manipulación informativa}

Una de las primeras medidas que tomaron los países involucrados en el conflicto fue el control y centralización de las comunicaciones. Gran Bretaña tomó la iniciativa. Desde agosto de 1914 creo tres organismos de prensa y propaganda desde el gobierno, el ejército y el Foreing Office "para evitar resquicios en los asuntos informativos nacionales e internacionales" (Bordería, 1998: 357). Este ejemplo fue seguido por Francia, con la Maison de la Pesse, y en Estados Unidos por el comité de Información Pública dirigido por G. Creel.

Las agencias internacionales de prensa ingresaron en este esquema, e incluso las empresas que brindaban los soportes técnicos para la transmisión informativa, tomaron partido abiertamente. Por ejemplo, el 3 de febrero de 1917, aun sin la certeza de que Estados Unidos rompiera relaciones diplomáticas con Alemania, la empresa Marconi Wireless Company "telegrafió al Wilson poniendo a su disposición todas sus estaciones inalámbricas con todo su equipo y personal que las sirven" (Diario Oficial de El Salvador, 2-2-1917, p. 4). Marconi había demostrado la importancia del servicio de la telegrafía sin hilos; tan solo cinco años antes, el servicio de Marconi permitió que se salvaran 865 personas tras el hundimiento del Titanic. 
La toma de posición de las empresas informativas es explicable en la medida en que cada una responde a su país de origen. La Reuter es la agencia oficial del gobierno británico y la Associated Press (AP) está conformada por los principales periódicos de los Estados Unidos. Se había unido en 1857 a la Telegraphic and General News Association y en 1892 adquirió el nombre de Associated Press y trataba entonces con los periódicos de toda la Unión. La Guerra fue una oportunidad sin precedentes para la AP que le permitió expandirse por todo el mundo. Para 1917, se ufanaba de sus 52000 corresponsales especiales.

Tanto la Reuter como la Havas vendían noticias a la AP la cual transmitía y distribuía en forma exclusiva en Estados Unidos y algunos países americanos. Como ocurrió en las naciones europeas implicadas en el conflicto, en Estados Unidos el control de la información por parte del gobierno fue determinante. "Una semana después de la declaración de guerra, Wilson nombró un Comité de Información Pública. Su labor primordial era diseminar hechos concernientes a la guerra. Debía también coordinar la propaganda del gobierno y servir de enlace entre éste y la prensa" (Emery, 1966: 580). Este comité pronto siguió el ejemplo de la Wellington House, agencia de propaganda de la Gran Bretaña, en la publicación de un boletín semanal con informes de guerra acompañado de fotografías, grabados y matrices.

Además de la comercialización de noticias, la AP “celebró ... contratos con Reuter, y por intermedio de ésta ..." (Weil, 1994: 210) con la agencia francesa Havas y la alemana Wolff para distribuirse los clientes geográficamente y la AP resultó poseedora de Centroamérica y el Caribe.

"Hicieron coincidir las áreas de influencia político económica con las áreas de influencia informativa... (por ello) las agencias tuvieron una política informativa supeditada a los intereses de estado, ... durante toda su existencia, la verdad de la Reuter era la verdad del Imperio Británico, la de la Havas... era la del Estado Francés, la de la Wolff era la del Estado alemán y la de las americanas traducía los intereses de los grupos de presión ligados en la vida y en la muerte, en la pobreza y en la enfermedad con las razones de un estado hecho a su medida" (Montalván, 1980: 194).

Para brindar el servicio, la AP hacía uso de las instalaciones de la United Fruit Company (UFCO), uno de los principales grupos de presión que controlaba el tráfico de despachos noticiosos a través de su dependencia Tropical Radio Telegraph Company (TRTC).

Las instalaciones inalámbricas de la TRTC dejaban mucho que desear en Centroamérica. En mayo, la prensa costarricense publicó una enérgica nota advirtiendo del mal estado de las líneas telegráficas "en lo que corresponde a la sección de Nicaragua". La situación era realmente grave; así lo evidenciaba el reporte que hiciera la delegación gubernamental que acompañó al Agente Confidencial de Estados Unidos, Mr. Foster Dulles, a una visita a la frontera norte de Costa Rica, a la altura de Sapoa. Indicaba textualmente: 


\begin{abstract}
"No es imaginable el pésimo estado de descuido en que se encuentran aquellas líneas telegráficas; permanecen caídas en trechos de kilómetros enteros y prestan servicio solo porque no han quedado colgando de los garfios del enjambre de higuerillas que cubren abundantemente los potreros y sobre las ramas de los árboles los postes usados para esas líneas son tan débiles que cualquier viento los bota; las conexiones en los aisladores están muy mal hechas; en fin que aquello es un verdadero desastre y, con esos desperfectos en aquellas líneas, mucho hace el telégrafo con mantener el irregular servicio con el exterior y resto de Centroamérica de que nos servimos actualmente" (La Información, 8-5-1917, p.1).
\end{abstract}

Esta situación afectaba periódicamente dejando a los diarios sin noticias internacionales del servicio ordinario. El 13 de mayo, las fuertes y prolongadas lluvias impidieron la recepción de cablegramas (La Información, 13-5-1917, p. 3) y el 24 de junio, (La Información, 24-6-1917, p. 3) se repitió el problema.

A estas dificultades se sumaba otra que preocupaba grandemente a los editores del periódico. Las noticias llegaban, procedentes de Nueva Orleans, a San Juan del sur en inglés y allí, un traductor, las trasladaba al español y las enviaba de Nicaragua a Costa Rica. Las traducciones, sin embargo, eran lamentables según la nota del diario La Información del 10 de mayo, tanto que se veían obligados a invertir tiempo y esfuerzo en la interpretación y corrección de los despachos -con la consecuente "reinterpretación" y por ello tergiversación, de las noticias-. La solución propuesta era satisfacer la necesidad que tenía Costa Rica de contar con una estación cablegráfica propia y no depender de la estación ubicada en territorio nicaragüense (La Información, 10-5-1917, p. 1).

Los problemas de traducción aunado a la ausencia periódica de cables más la censura y control de las noticias en los países de origen de las agencias informativas, conducen a suponer que la información sobre los diversos y complicados escenarios del conflicto divulgada en los diarios, era poco confiable.

Pero la tergiversación informativa y la censura eran frecuentes, a juzgar por la queja constante de los bandos querellantes. Uno y otro acusaba a las empresas noticiosas de manipular a su favor, las informaciones. En mayo de 1917, el diario salvadoreño reproducía un cable acusando a los diarios alemanes de guardar silencio sobre diversos sucesos pero hacía referencia de inmediato a que un crítico de prensa de nacionalidad alemana "sigue previniendo a sus lectores, contra los comunicados mal intencionados de los franceses, relativos al hundimiento del Lusitania, el cual dice, iba cargado de municiones y su hundimiento salvó la vida tal vez de 100.000 alemanes; y concluye excitando al pueblo a que continúa proveyendo de cañones y municiones a los tiradores alemanes hasta obtener la victoria" (Diario Oficial de El Salvador, 9-5-1917, p.2), de manera tal que la tergiversación de la información intenta el apoyo del pueblo alemán para los militares que participan en el conflicto. El 21 de junio el gobierno belga denunció oficialmente "la mala fe de la agencia Wolff, que continúa negando las deportaciones belgas" que persistían sin cesar desde el 10 de febrero de 1917 (Diario Oficial de El Salvador, 21-6-1917, p. 2). Según el diario La Información de Costa Rica, "los alemanes para mantener el espíritu en su patria 
publican falsos informes de lo que sucede en el frente" (La Información, 23-5-1917, p. 2).

Por su parte, los alemanes también acusaban a los aliados de tergiversar las noticias a su favor. En enero, tras un ataque sorpresa, los alemanes, afirmaron que arrasaron las huestes francesas en Le Morthomme, mientras que éstos últimos aseveraron que las fuerzas germanas fueron fácilmente rechazadas (Diario Oficial de El Salvador, 3-1-1917, p. 1).

Uno de los errores de la estrategia comunicativa alemana es que "consumían buena parte de sus energías anunciado que la propaganda de los aliados era falsa e injusta y haciendo laboriosos esfuerzos por corregir lo que consideraban impresiones falsas... el intento de corregir la propaganda injusta tuvo el simple efecto de refrescar en las mentes de los receptores las declaraciones originales y de difundirlas entre aquellos que, de otro modo, no hubiesen oído hablar de ellas." (Bordería, 1998: 359).

El manejo de las noticias se presentaba incluso al interior de los mismos países neutrales. Por ejemplo, el periódico salvadoreño anotaba que "Colombia ha dado pasos para atajar la campaña de prensa colombiana infamatoria [sic] con Estados Unidos de Norte América" (Diario Oficial de El Salvador, 6-6-1917, p. 2). En abril, La Información hacía alusión a la censura aplicada, a partir de ese momento, a todos los cables que ingresaran al Istmo panameño (La Información, 10-04-1917, p. 1).

Las acusaciones sobre la instalación de redes inalámbricas en distintos puntos de América Latina por parte de Alemania, fueron frecuentes. En junio, cuando se temía que Alemania se aliara con los rebeldes mexicanos - Pancho Villa y Emiliano Zapata-, el Diario Oficial de El Salvador informaba que "hay razón para creer que México posee una estación de telegrafía inalámbrica que es capaz de comunicarse con Alemania", pero de inmediato aclaraba "indudablemente existen estaciones inalámbricas allí; pero sábese [sic] que todas están controladas por el gobierno, quien no se atrevería a violar su actitud de neutralidad" (Diario Oficial de El Salvador, 6-6-1917, p.2.). La nota seguida hacía alusión a la presencia de agentes alemanes en Argentina haciendo gestiones para "establecer allí una estación de telégrafos sin hilos" [sic], esta vez no hay aclaración. De igual manera, en marzo se aseveraba que agentes alemanes trataban de restablecer la estación inalámbrica en la Isla de San Andrés, "situada a 230 millas al norte de Colón (Panamá) suprimida desde el principio de la guerra por el gobierno de Colombia en virtud de representaciones de Gran Bretaña" (Diario Oficial de El Salvador, 21-3-1917, p. 2).

La preocupación por la presencia de estaciones clandestinas también permeó en Costa Rica. En mayo de 1917, el jefe de la guardia rural de Heredia, desmanteló una estación radiográfica, de corto alcance según la noticia, pero dadas las circunstancias bélicas, era necesario destruir todo estación radiográfica en el país, por más inofensiva que demostraran ser (La Información, 13-4-1917, p. 4).

La censura estaba presente en todos los países involucrados pero no se limitaba solo a la prensa pues en febrero, el periódico salvadoreño expuso que "La dirección 
de seguridad [de los Estados Unidos] pone bajo censura los discos de gramófonos y fonógrafos tras descubrir que los alemanes se valían de este medio de espionaje para transmitir de noticias militares" (Diario Oficial de El Salvador, 17-2-1917, p.2).

\section{Los temas noticiosos}

La absoluta mayoría de las noticias internacionales que divulgan ambos diarios en el primer semestre de 1917, se referían a la Guerra que se había desatado en Europa desde junio de 1914. De estas informaciones, una buena cantidad, en los dos periódicos, defendían y exaltaban la causa aliada, el avance y el triunfo de la triple entente y de sus colaboradores, que para el primer semestre de 1917, sumaban más 10 países -Francia, Reino Unido, Rusia, Serbia, Bélgica, Japón, Italia, Rumanía, Estados Unidos y Grecia- en lucha contra los Imperios Centrales conformados por Alemania, Austria-Hungría y Bulgaria que se incorporó en 1915.

La postura estaba tan definida, que cualquier opinión divergente era considerada enemiga. Por ejemplo, el 5 de febrero, el diario salvadoreño publicó una noticia procedente de Nueva York en la que advertía que George Sylvester Vierrdk (sic), editor de un periódico menor en Estados Unidos, a quien supuso era

\footnotetext{
“agente de Alemania en Estados Unidos publicó en su periódico lo siguiente: Hay que considerar como una calamidad la ruptura de relaciones entre Estados Unidos y Alemania, porque ella cerraría las puertas a la paz, vehementemente ansiada ahora por todos los pueblos de la tierra. Por ser consecuentes, Estados Unidos debiera romper sus relaciones con la Gran Bretaña, porque ésta tiene minado el Mar del Norte, poniendo así en peligro todo buque mercante, culpable o inocente. La acción de Gran Bretaña es, por lo tanto, más censurable que la de los submarinos, porque éstos pueden hacer concesiones especiales a los barcos norteamericanos. Toda acción de parte de Alemania para Gran Bretaña es ahora justificable. Si se confirma la ruptura de relación a ¿cuál será la potencia neutral que demande a los beligerantes la estricta observancia de la destrucción de Londres? ¿Quién pudiera en su oportunidad, demandar la paz si Estados Unidos se torna en zarpa de la Gran Bretaña" (Diario Oficial de El Salvador, 6-2-1917, p.3).
}

El editor Sylvester cuestionaba la ruptura de relaciones entre Estados Unidos y Alemania, razón por la cual se le califica de "agente de Alemania en Estados Unidos" (Diario Oficial de El Salvador, 6-2-1917, p. 3).

Como evidencian los Gráficos 1 y 2, uno de los temas más frecuentes en ambos periódicos, son los ataques alemanes a países ubicados en Europa, América e incluso Asia. La Información concede el primer lugar, a los avances que Inglaterra logra en sus diversas incursiones. La cuantía de notas sobre este asunto se explica por la presencia diaria del boletín del gobierno británico que se incorpora en la página 7 del diario y se publica en idioma inglés. Por lo general, resume las operaciones efectuadas durante la semana y exalta los triunfos de Gran Bretaña en el conflicto. Esta sección no existe en el diario salvadoreño. 
Los ataques alemanes se refieren a las sangrientas, sorpresivas y violentas incursiones de ese bando sobre posiciones y territorios europeos o americanos.
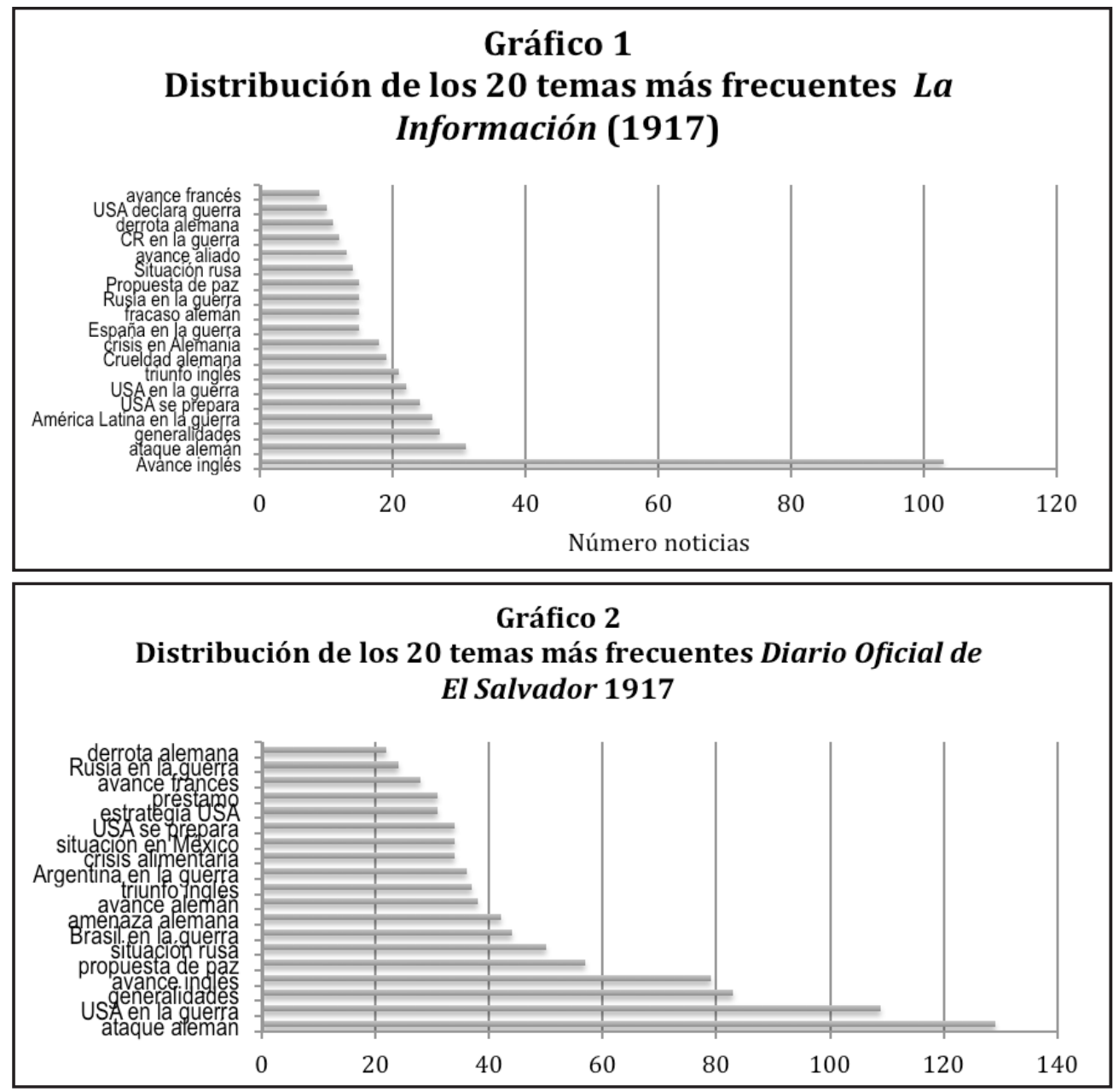

Los ataques alemanes, según los cables publicados por ambos periódicos, generalmente no tuvieron éxito o fueron rápidamente sofocados por las huestes aliadas. Por ejemplo, el 10 de febrero el periódico de El Salvador publica una noticia procedente de París indicando que las fuerzas alemanas "atacaron nuestras posiciones en la región de Embernil, situada en la Lorena, y lograron penetrar a las trincheras avanzadas; pero inmediatamente después fueron rechazadas por medio de un contraataque, estableciéndose nuestra línea de fuego" (Diario Oficial de El Salvador, 10-2-1917, p. 2). 
Una de las constantes en el manejo informativo en uno y otro bando, fue mostrar al enemigo como perverso, incauto, descuidado, agónico y destacarse a sí mismos como los defensores del bien, la justicia y la paz.

En contadas oportunidades -3.11\%- el diario salvadoreño le atribuye a Alemania o a Austria, triunfos en las batallas. El 13 de febrero de 1917, por ejemplo, se publicó el siguiente cable:

"Viena, 12._Durante varios ataques en la región de Gorizia ganamos varios puntos de trincheras enemigas, causándole a los adversarios fortísimas pérdidas. Apresamos 15 oficiales y 650 hombres de tropa, conquistando a la vez, 10 ametralladoras, 2 lanza minas y mucho material de guerra." (Diario Oficial de El Salvador, 13-2-1917, p. 2)

El periódico costarricense divulgó solo un $0,60 \%$ de noticias sobre algún avance alemán y de hecho, las informaciones eran tan vagas, que podrían interpretarse como avances relativos pues en cada uno se genera un triunfo aliado. Solo en muy escasas ocasiones se admite alguna derrota aliada. El 3 de abril, el diario acepta la desastrosa situación para los aliados en Somme titulando la noticia "Se hace imposible ocultar a los soldados que se retiran, abandonando sus mejores posiciones, la verdad del desastre del Somme" (La Información 3-4-1917, p.1).

Las estrategias de comunicación de los gobiernos en los países beligerantes estaban dirigidas a obtener el apoyo de la opinión pública, no solo para lograr la colaboración de los ciudadanos, sino también para quebrantar la posible indiferencia u hostilidad hacia la intervención en la guerra. La persuasión consistió en gran parte, en presentarse como víctimas de la agresión externa. Se ocuparon de bombardear a la población con historias atroces del enemigo y mantener así el odio a los ejércitos contrarios y el orden en la retaguardia (Bordería, 1998: 356).

Tres asuntos más fueron determinantes en los impresos: las diversas y siempre rechazadas propuestas de paz, la situación de Rusia y la participación de Estados Unidos en el conflicto. De hecho, en 1916, la imposibilidad de finalizar la guerra puso en aprieto a los beligerantes. Durante 1917 se desencadenaron protestas de soldados, trabajadores de la industria metalúrgica -particularmente seria en Francia-, que fueron violentamente reprimidos. La escasez de víveres y de pertrechos, más la dureza de los combates en las trincheras, condujeron a situaciones insostenibles en todas las potencias involucradas.

La guerra había desgastado a los países beligerantes. Después de 3 intensos años de luchas constantes, las propuestas de paz de uno u otro bando fueron tan frecuentes como repetidos fueron los rechazos. Los periódicos hacían eco de los planes emanados de los dos bandos pero destacando siempre las exigencias poco realistas de la Entente. Por ejemplo, en enero de 1917, La Información señala en su titular principal que "al contestar Wilson a la entente pedirá la evacuación de Francia y Bélgica con indemnizaciones" (La Información, 7-1-1917, p.1). Tres semanas después, el mismo periódico destaca que "La Entente resuelve adoptar medidas más definitivas para limpiar de enemigos el Mediterráneo [y agrega con punto y seguido] El Kaiser toda- 
vía insiste en la paz" (La Información, 29-1-1917, p.1). En febrero del mismo año, el periódico rotula la noticia principal con un titular que no deja lugar a dudas respecto a la imposibilidad de aceptar una propuesta de paz alemana: "Por qué Alemania pide la paz?. Porque camina hacia una crisis de transportes" (La Información, 23-2-1917, p.1). Todavía en abril, con la intención de evidenciar la crítica situación de los Imperios Centrales, La Información acentúa en el primer titular: "Austria desangrada y decepcionada de la guerra está tratando de hacer la paz. Se cree que sus iniciativas son sugeridas por Alemania" (La Información, 21-4-1917, p. 1), por tanto, debía ser rechazado ad portas.

Por su parte, el Diario Oficial de El Salvador mencionaba con mayor reiteración la postura alemana y austriaca respecto a las propuestas de paz. Por una parte, informaban que la Triple Entente lamentaba que los aliados no acepten sus propuestas de paz (Diario Oficial de El Salvador, 3-1-1917), y que ellos por su parte rechazaban las propuestas "por considerar que sus enemigos quieren la destrucción de Alemania (Diario Oficial de El Salvador, 8-1-1917) o se introduce en sus asuntos internos (Diario Oficial de El Salvador, 10-01-1917). Por su parte, los aliados indican que aceptarían la paz si figura en la propuesta la independencia, indemnización y rectificación de fronteras de Bélgica y la devolución de las provincias irredentas a Italia y el acceso de Rusia al mediterráneo por los Dardanelos" (Diario Oficial de El Salvador, 12-1-1917).

Las propuestas de paz fracasaron entonces por asuntos que rebasan los argumentos que los periódicos expresan. Francia no aceptaba ninguna condición que no garantizase la devolución de Alsacia-Lorena, Alemania no estaba dispuesta de perderlas. "Gran Bretaña había entrado en la guerra para restaurar la soberanía de Bélgica, pero ahora la armada alemana tenía claro que el acceso a los puertos del Canal era vital para la futura seguridad de Alemania..." (Strachan, 2004: 234).

En síntesis, los periódicos apostaron por continuar con la guerra e insistieron en su notas, en la imposibilidad de ambos bandos de aceptar las condiciones que se proponían pero en particular, abrigaban la esperanza de que la crisis interna alemana, específicamente la crisis alimentaria, lograra acabar con la participación de los Imperios Centrales en el conflicto.

Efectivamente, la carencia de alimentos es indudablemente un problema para Alemania pero lo era también para los países en guerra. Aunque la prensa centroamericana apenas lo menciona, países como Suecia, Polonia, Rusia, Holanda, Francia y la misma Inglaterra, se vieron obligados a controlar la cebada, el trigo y la avena para abastecer a la población. Incluso en Lisboa la crisis alimentaria provocó motines por el pan en 1917 (Diario Oficial de El Salvador, 5-6-1917, p. 3). En Francia, los precios de la comida habían subido un $40 \%$ en enero de 1917 desde que inició la guerra y para junio, el 92\% mientras los salarios reales cayeron un 10\% (Strachan, 2004, 257).

El periódico costarricense es mucho más enfático que su homólogo en magnificar la crisis alemana. En enero advertía que en ese país hay "motines generales por causa del hambre general" (La Información, 11-1-1917, p. 1) y el gobierno tuvo "que tomar 
a su cargo la alimentación de las masas hambrientas de muchas ciudades" (La Información, 16-1-1917, p.1), el problema fue originado, según los titulares del periódico, por "el fracaso de los cálculos hechos por los economistas alemanes respecto del monto de los comestibles, [lo que] lleva al pueblo la última evidencia del desastre interior en el Imperio" (La Información, 31-3-1917, p.1).

Pero no solo la crisis dará a traste con las pretensiones de la Entente según la prensa, pues a su criterio, las diferencias entre Austria y Alemania podrían provocar una ruptura de relaciones y por ello, el debilitamiento de los Imperios Centrales. En mayo, el diario de El Salvador indicaba que según el editorial del impreso austriaco, órgano de Czernin, "Sozial Demokraten Fremdenblatt", Austria y Alemania tenían intereses políticos diferentes con respecto a Polonia y a la negociación de paz por separado, con Rusia. Austria le reclama a Alemania el no haberla ayudado a repeler la invasión rusa en sus fronteras (Diario Oficial de El Salvador, 1-5-1917, p.2).

Rusia, por su parte, constituía para 1917 un problema más que un apoyo para los aliados. Con su revolución interna, escasez de víveres y los continuos descalabros militares, más los motines constantes, era poco lo que podía hacer por mantenerse en el frente. Los aliados presionaron por todos los medios posibles para que se permaneciera en la guerra, sin embargo para octubre de 1917 la retirada fue inevitable, tras el golpe de estado que acabó con el gobierno burgués de Kerensky y encumbró el poder a los comunistas de Lenin. Desde enero de 1917, la prensa especulaba sobre la situación rusa, su papel en la guerra y el supuesto acuerdo bilateral de paz con Alemania y Austria. La Información, el 16 de mayo aseveraba que "Rusia renueva sus propósitos de seguir en la guerra al lado de los aliados hasta obtener la victoria final" (La Información, 16-5-1917, p.1) y destacaba el repudio de socialistas y del gobierno ruso de firmar la paz por separado con Alemania. En otros términos, es muy importante para el periódico mantener la esperanza de que Rusia se permanecería en la guerra y que a diferencia de lo Imperios Centrales, en el bando de los aliados no había conflictos.

El tema por excelencia durante el primer semestre de 1917 fue la participación de Estados Unidos en la guerra. Desde el inicio del año, los periódicos insistían en las amenazas y ataque alemanes contra Estados Unidos. No solo se trataba de manejos políticos sino también de bombardeos a buques y vapores norteamericanos.

Estos y otros hechos, amen de la insistencia de los aliados para que Estados Unidos ingresara abiertamente en el conflicto, condujo a la ruptura de relaciones diplomáticas en febrero de 1917 y a la declaratoria de guerra en abril del mismo año.

\section{La ruptura de relaciones de Estados Unidos con Alemania}

El 3 de febrero de 1917, Estados Unidos rompió relaciones diplomáticas con Alemania, tras los peligros que la guerra suponía para los buques estadounidenses (Strachan, 2004: 235). 
El periódico salvadoreño reprodujo justo el día 3, un cable aseverando que la decisión del gobierno de Estados Unidos aun no se había tomado (Diario Oficial de El Salvador, 3-2-1917, 4).

El día anterior, publicó cuatro notas enviadas por la agencia Reuter que a su vez, copiaban las opiniones emitidas por los periódicos Herald de Boston, The Sun de Baltimore, The Post de Denver ${ }^{1}$ y Picayune ${ }^{2}$ de Nueva Orleans. Todos insistían en que las provocaciones alemanas "no le deja más camino a Estados Unidos que cortar sus relaciones diplomáticas". Picayune detallaba que Alemania "ha tirado el guante de Estados Unidos, quizá con la deliberada intención de poner a prueba su política, por lo cual el Tío Samuel, no puede ahora ni evadir ni postergar una resolución..." The Sun es categórico: "Estados Unidos no debe contemporizar más con la matanza de ciudadanos americanos; por consiguiente, su deber es romper las relaciones con Alemania" (Diario Oficial de El Salvador, 2-2-1917, p. 1).

A renglón seguido y a pesar de la insistencia de la prensa llamando abiertamente a la guerra, el Diario Oficial de El Salvador publica un cable procedente de Washington mesurando la decisión: "los círculos oficiales se muestran muy reservados acerca de la naturaleza de la comunicación que está por enviarse a Alemana, en relación con su guerra submarina..." (Ibíd).

El 4 de febrero no circuló el periódico y los cables del día siguiente hacían referencia a la situación de los 3000 ciudadanos estadounidenses residentes en Alemania tras la ruptura de relaciones. En la misma lista de despachos, se reprodujo uno en el cual Wilson advertía a Alemania que de repetirse ataques como el ocurrido en el Canal de la Mancha, donde submarinos alemanes hundieron el vapor Sussex en el que viajaban ciudadanos estadounidenses, romperá relaciones (Diario Oficial de El Salvador. 6-2-1917, p. 3).

No será sino hasta el 7 de febrero cuando el periódico salvadoreño asevera que la ruptura efectivamente se dio.

En contraste con la tímida información ofrecida por el diario oficial salvadoreño, La Información de Costa Rica hizo un despliegue durante cuatro días en notas de primera página. Inició el lunes 4 de febrero advirtiendo del la posibilidad de que las relaciones entre Alemania y Estaos Unidos se rompieran si la campaña submarina alemana continuaba (La Información, 4-2-1917, p. 1). El martes 6 el periódico emitió un recuadro al centro de la primera página con el "anuncio oficial de la ruptura de relaciones de los Estados Unidos con Alemania" Indicaba que "el rompimiento de relaciones diplomáticas con Alemania fue anunciado formalmente al país y al mundo por el Presidente Wilson en una sesión conjunta del Congreso, a las 2 p.m. de hoy

1 Diario Democrático fundado en Denver, Colorado, en 1892, para difundir los ideales políticos. (Hosakawa, 1976).

2 Diario matutino que nace en 1914 de la fusión de dos periódicos, Times y Picayune que circulaba desde 1830. Llegó a ser el periódico más poderoso del sur. Con altibajos, logró mantenerse hasta 1989. (1914: two newspapers merge to create The Times-Picayune. En:http://www.nola.com) 
(3 de febrero)... (La Información, 6-2-1917, p. 1). Al siguiente día continuaba brindado los detalles de las consecuencias de la ruptura: la retirada de los cónsules, las medidas para tripulantes alemanes, el manejo de los intereses americanos en Alemania por parte de España y además suponía que "El Presidente Wilson [mantuviese una] conferencia con sus Ministros acerca de las medidas para la preparación de la Guerra", entre otros asuntos. El jueves 8, lanzaron como noticia de apertura el siguiente titular: "Los Estados Unidos castigarán con la espada a Alemania que los ha retado a un combate mortal" (La Información, 8-2-1917, p. 1).

De acuerdo con el manejo informativo de la prensa, la participación de Estados Unidos fue obligada por las provocaciones alemanas que estaban afectando las vidas de los ciudadanos norteamericanos.

A partir de este momento, recrudece y se intensifica la insistencia de La Información en la urgencia de que Estados Unidos ingrese en la guerra. Todas sus notas de primera página tienen esa intencionalidad. De hecho, el segundo titular del 8 de febrero no deja lugar a duda "En Nueva York hay un gran entusiasmo por la guerra y se canta el Himno Nacional en las manifestaciones públicas" (Ibíd.).

Las noticias sobre la ruptura de relaciones continúa en las ediciones siguientes hasta que se inicia la discusión y luego el Congreso de los Estados Unidos, toma la decisión de declarar la guerra a la los Imperios Centrales.

A pesar de que los dos periódicos se nutren de las dos agencias de prensa que le dan servicio a Centroamérica: Reuter y AP, las noticias que se divulgan no son iguales y solo en escasas ocasiones, coincidentes. En la tabla 1, se comparan las informaciones divulgadas por ambos diarios el día 6 de febrero cuando se da el anuncio de la ruptura de relaciones:

Tabla 1. Noticias sobre la ruptura de relaciones entre Estados Unidos y Alemania de los periódicos Diario Oficial de El Salvador y La Información

\begin{tabular}{|l|l|}
\hline Diario Oficial de El Salvador (6-2-1917) & La Información (6-2-1917) \\
\hline Se reúnen en Panamá para resguardar el Canal & $\begin{array}{l}\text { La difícil situación con Alemania unifica todos } \\
\text { los partidos de Norteamérica y todo el país se } \\
\text { dispone a proceder con energía }\end{array}$ \\
\hline $\begin{array}{l}\text { Wilson y EEUU desean la paz, pero podríamos } \\
\text { llegar a enfrentarnos }\end{array}$ & $\begin{array}{l}\text { Anuncio oficial de la ruptura de relaciones de } \\
\text { Estados Unidos con Alemania }\end{array}$ \\
\hline $\begin{array}{l}\text { Alemanes amenazan con submarinos } \\
\text { industrias británicas }\end{array}$ & $\begin{array}{l}\text { De París avisan que los Embajadores } \\
\text { americanos en Berlín y Viena regresan por vía } \\
\text { de Barcelona }\end{array}$ \\
\hline $\begin{array}{l}\text { Incita a la población a armarse y no perder } \\
\text { tiempo en pedir la paz }\end{array}$ & $\begin{array}{l}\text { Gran victoria de los ruso-rumanos en } \\
\text { Kinpoulong }\end{array}$ \\
\hline $\begin{array}{l}\text { Submarino alemán hunde vapor } \\
\text { norteamericano Housatonic que transportaba } \\
\text { trigo }\end{array}$ & $\begin{array}{l}\text { La posible guerra entre Alemania y Estados } \\
\text { Rica y los intereses económicos de Costa }\end{array}$ \\
\hline $\begin{array}{l}\text { Brasil apoyará a EEUU en caso de guerra con } \\
\text { Alemania }\end{array}$ & Alemania contra el mundo \\
\hline
\end{tabular}




\begin{tabular}{|l|l|}
\hline Diario Oficial de El Salvador (6-2-1917) & La Información (6-2-1917) \\
\hline Es un hecho la guerra entre Alemania y EEUU & $\begin{array}{l}\text { Wilson's decision to sever Diplomatic relations } \\
\text { (sic) with Germany has caused sensation in } \\
\text { neutral countries }\end{array}$ \\
\hline Gobierno brasileño apoya a EEUU & Continuación de la página 1 \\
\hline $\begin{array}{l}\text { Fuerte golpe francés contra las trincheras } \\
\text { alemanas }\end{array}$ & \\
\hline $\begin{array}{l}\text { Ruptura de relaciones genera reacciones } \\
\text { estados neutrales europeos y Suramérica. } \\
\text { Gobierno Brasileño apoya a EEUU }\end{array}$ & \\
\hline $\begin{array}{l}\text { En Italia celebran unión de los EEUU a la } \\
\text { Entente }\end{array}$ & \\
\hline Ruptura de relaciones no significa guerra & \\
\hline $\begin{array}{l}\text { 1000 telegramas llegan a Casa Blanca con } \\
\text { apoyo a EEUU sobre ruptura de las relaciones }\end{array}$ & \\
\hline $\begin{array}{l}\text { Personal de la Embajada Alemana en EEUU } \\
\text { prepara su salida del país }\end{array}$ & \\
\hline $\begin{array}{l}\text { Alemania anuncia continuar sin restricción } \\
\text { guerra de submarinos }\end{array}$ & \\
\hline $\begin{array}{l}\text { Buque brasileñó Amazon destruyó submarino } \\
\text { alemán }\end{array}$ & \\
\hline $\begin{array}{l}\text { Extraoficialmente EEUU y Alemania } \\
\text { rompieron relaciones }\end{array}$ & \\
\hline
\end{tabular}

En los días anteriores o siguientes, tampoco hay coincidencia. Esto se debe en parte a que La Información paga un servicio adicional de despachos que recibe diariamente. A diferencia de su par en El Salvador, los dueños del impreso costarricense recibían el servicio ordinario de noticias cablegráficas que ingresaba a razón de 2000 palabras diarias y el gobierno distribuía entre los periódicos que circulan en el país, y el servicio especial que compraban a "la Agencia Reuter y los Aerogramas del servicio oficial de la United Fruit Co.” (La Información, 13-5-1917, p. 4), que corresponde a los cables de la prensa asociada.

\section{Las noticias sobre la declaración de Guerra}

El 2 de abril de 1917, el Presidente Wilson se presentó ante el Congreso un extenso discurso solicitando la autorización para declararle la guerra a Alemania. Cuatro días más tarde, el Senado aprobó la iniciativa con 82 votos a favor y 6 en contra. La noticia se publicó en grandes titulares en el periódico La Información el martes 10 de abril y en el Diario Oficial del Salvador se afirma desde el día 3 y se confirma el 9 pues no circuló el impreso los días 5, 6, 7 y 8 de abril por razones no aclaradas.

El tratamiento de la información en ambos diarios fue distinta. Por una parte, el Diario Oficial de El Salvador resumió el discurso destacando la vehemencia y claridad de la disertación y enfatizando que responde a los ataques sufridos por parte del gobierno alemán. La Información, por su lado, dedicó dos días al evento: el 4 y 5 de 
abril. Enfatizó el primer día, la franqueza del Presidente Wilson e igual que su homólogo, insistió en que la declaratoria es la respuesta a los ataques alemanes. El día 5, reproduce textualmente parte del discurso del primer mandatario estadounidense.

La prensa tomó partido inmediatamente con los Estados Unidos. Exaltó con entusiasmo la iniciativa del Ejecutivo. Habían conseguido una de sus finalidades: lograr el ingreso abierto y decidido de los Estados Unidos en el conflicto:

"El mensaje del Presidente Wilson al Congreso, dice el "New York World", más que una expresión de patriotismo es una apelación a la nación, hecha con todo el impulso de que es capaz la tradición y la democracia americanas. Su razonamiento es admirable. El Presidente toca la cuestión de fondo, y al Congreso no le queda más recurso que responder sin tardanza a la excitativa que se le hace para la defensa nacional, en nombre del honor y la libertad americanas. Wilson no conoce el miedo y su palabra franca y clara revela el carácter del hombre que lucha por los fueron de la humanidad y los derechos del pueblo americano. El país entero debe sentirse orgulloso de tener a su frente un caudillo que sabe dirigir los intereses de la comunidad por el sendero del deber, por lo tanto debe olvidar sus vacilaciones anteriores. "La Tribuna" dice: jamás en la historia de Estados Unidos hemos tenido un jefe de Estado que haya interpretado tan de ceca los ideales del pueblo americano, como el presidente Wilson, el cual es un mandatario ideal que gusta de todos los americanos, y por tanto cuenta con el apoyo de éstos. El "Herald" dice: El deber del Presidente es unirse a la Entente y combatir con ésta por la libertad." (Diario Oficial de E Salvador, 4-4.1917, p.1.)

La prensa costarricense no tarda en publicar un editorial exultante de apoyo. Entre otros halagos aseveró:

"Los Estados Unidos al lanzarse a la guerra, se convierten en campeones mundiales del derecho de gentes, de la libertad de los mares, del respeto a los neutrales; todas esas causas nobles llevan en su escudo al entrar en el estadio y por eso los acompaña la simpatía mundial. Nosotros ardientemente deseamos que obtengan la victoria más completa; que contribuyan eficazmente a asegurar la libertad de los mares mientras no pueda ser restringida con los medios propios y de acuerdo con los principios de derecho, que cacen los submarinos y venguen a los piratas que los tripulan...

Adelante, Tío Samuel, adelante con tus heroicas legiones de soldados jóvenes y fuertes como efebos roanos, patriotas como espartanos; hay un sitio para tu águila en los campos de lucha de Europa, donde su aleteo llenará de regocijo los corazones, de entusiasmo los pechos de los leales y abnegados legionarios, que allá defienden la causa de la civilización” (La Información, 5-5-1917, p. 5).

La actitud de la prensa centroamericana es deudora en buena medida, de las potentes y efectivas campañas de propaganda exterior que había emprendido Gran Bretaña desde el inicio del conflicto, dirigidas a países amigos, enemigos y neutrales. Estados Unidos había mantenido desde el principio de la contienda, una actitud "aislacionista" relativa pues estaba consolidando la intervención económica en América Latina que había iniciado desde mediados del siglo XIX y el recién conflicto con Cuba (1898), había marcado el principio de la expansión imperialista de los Estados Unidos fuera de las fronteras continentales. 
Ciertamente la campaña propagandística fue favorecida por una serie de factores que condujeron a tomar la decisión de participar abierta y decididamente en el combate: Por una parte, cerca del $50 \%$ de la población estadounidense "tenían descendencia de anglosajones; en 1917, los gobierno aliados debían a los Estados Unidos 2.300 millones de dólares, mientras las potencias centrales sólo habían recibido préstamos por 23 millones, el peso de la deuda condicionó el signo de la intervención para los hombres de negocios" (Bordería, 1998: 358).

Las campañas propagandísticas de Gran Bretaña en territorio estadounidense se acrecentaron desde 1915, cuando se creó en la potencia americana, un departamento similar al Foreing Office, institución de prensa y propaganda con sede en Londres que se inauguró en agosto de 1914, justo en el momento de inicio de la crisis, precisamente para el control y manejo de los asuntos informativos nacionales e internacionales. Uno de los objetivos de esta oficina en Estados Unidos era la captación de corresponsales americanos en Londres "e influir en la visión que del conflicto transmitían a sus compatriotas" (Ibid), los mismos que nutrían de información internacional a los periódicos centroamericanos.

\section{Conclusión}

La evidencia indica que la prensa centroamericana llamó y incentivó la participación de Estados Unidos en la Primera Guerra Mundial. El gobierno norteamericano, a su vez, utilizó los periódicos para mostrarse como la potencia salvadora de un mundo que se hundía en el caos.

Ciertamente hubo dos detonantes que aceleraron el proceso: la guerra submarina sin restricciones que anunció el Kaiser en febrero de 1917 y el telegrama interceptado del Ministro de Exteriores Alemán, Arthur Zimmerman, donde indicaba al Embajador alemán en Washington, la posible alianza con México en caso de guerra entre Alemania y Estados Unidos.

Las agencias de prensa inventaban, agrandaban o exageraban los "ataques" alemanes a navíos en los que viajaban ciudadanos estadounidenses, publicaban noticias en las que aseveraban amenazas y provocaciones alemanas en territorio americano. La posibilidad de que los imperios centrales controlaran el envío y recepción de mensajes a través de estaciones inalámbricas, exaltaba a los impresos pues conocían bien el poder que la divulgación noticiosa tenía en la coyuntura de guerra.

En efecto, es claro que la prensa centroamericana, al menos los dos principales diarios de Costa Rica y de El Salvador, celebró la guerra porque ponía de manifiesto su fortaleza, la posibilidad de influir en la construcción de una opinión pública sedienta de noticias y por ello, las ventas de los periódicos ascendieron como nunca. Pero, de igual manera, el conflicto sacó a flote la debilidad: por una parte era un órgano informativo, pero por otro, era un medio propagandístico, dos funciones contradictorias para la prensa. 
Los dos bandos en disputa suprimieron de inmediato la libertad de prensa y asumieron el control imponiéndoles una minuciosa vigilancia para impedir que los impresos suministraran información al enemigo. Los usaron para propagar sus ideas.

La prensa expandía los detalles sobre la crisis alimentaria en Alemania, por ejemplo, pero no mencionaba los motines, las deserciones y las ofensivas del bando aliado.

La prolongación y la devastación resultante de la guerra más allá de todos los pronósticos, obligó a los gobiernos involucrados buscar mecanismos para convencer a la población civil y a los soldados, que se encontraban en el bando de la razón y la verdad y a ensayar formas para justificar una guerra sangrienta y absurda. Las estrategias persuasivas a través de un control de la información y del manejo de los medios de comunicación logró el objetivo, se ganaron la colaboración de los ciudadanos y la subordinación de los soldados. El precio que se pagó fue la eliminación de información comedida y veraz.

El control del caudal informativo que proporcionaba la guerra, condujo a través del convencimiento, a una estrecha colaboración entre el gobierno, la prensa y los militares. Esta relación favoreció el éxito de la propaganda británica. "Era evidente que nadie como la propia prensa, fogueada en los últimos decenios en los terrenos del sensacionalismo y el amarillismo, podía conocer los secretos de los lectores y los resortes, psicológicos y emocionales, y de este modo pulsar los mecanismos necesarios para lograr los efectos deseados". (Bordería, 1998: 358).

Pero además de manipular, la guerra tuvo varios efectos en la prensa centroamericana que se acentuaron cuando Estados Unidos decidió incorporarse: Las innovaciones propagandísticas demostraron ser ingeniosas y creativas, sobre todo en el manejo de los titulares y la ubicación del foco noticioso en sucesos que favorecían al bando aliado. Las secciones dirigidas a público de habla inglesa en su propio idioma para alcanzar a un grupo importante de lectores. La referencia a corresponsales de guerra, enviados especiales, despachos exclusivos, para darle a la fuente un rol clave en la veracidad de la información. Finalmente, la carestía de papel y las dificultades propias de la guerra, contribuyeron a la desaparición de diarios poco rentables.

En resumen, la prensa condujo a la guerra pero Estados Unidos también supo hacer uso de los periódicos para favorecer su imagen hasta el final del conflicto.

Por lo demás, en el marco de la política internacional del periodo, obtener el favor de los Estados Unidos y su apoyo económico, resultaba fundamental para el sostenimiento de los grupos políticos. Quienes gozaban del sostén de la potencia norteamericana, se garantizaban no solo su estadía en el gobierno sino también contar con el dinero necesario para el funcionamiento del aparato burocrático y por tanto, para mantener la estabilidad social, que no se logró en la mayoría de los casos.

En esos términos, la prensa cumplía su papel de "cómplice" de los grupos de poder $\mathrm{y}$ vocera de sus intereses. 


\section{Bibliografía}

AHVENAINEN, J. (1996). The History of The ribbean Telegraphs before the First World War. Helsinki: Suomalainen Tiedeakatemia.

BETANCOR, O. (2009). La postura aliadófila del diario "La Prensa" durante la Primera Guerra Mundial. Anuario de estudios atlánticos, ISSN 0570-4065, Núm. 55, pags. 343-366.

-- (2009). La Primera Guerra Mundial a través de las páginas del periódico "La Prensa". Anuario Tebeto de la Isla de Fuerteventura.

-- (2010) El cine a través de las páginas del diario "El Progreso" durante la Primera Guerra Mundial. Revista Vegueta, Universidad de Las Palmas de Gran Canaria (en línea).

-- (2010). La faceta periodística de Manuel Bethencourt del Río, en el diario "El Progreso" de Tenerife, durante la Primera Guerra Mundial. Anuario de estudios atlánticos, ISSN 0570-4065, No. 56, , pags. 199-222.

BORDERÍA, E., et. al. (1998). Historia de la comunicación social. Voces, registros y conciencias". Madrid: Editorial Síntesis.

COMPAGNON, O. "1914-18: The death throes of civilization The elites of Latinoamérica face The Great War". Disponible desde Internet en: http://univ-paris3. academia.edu. Consulta realizada el 8 de marzo, 2012.

HOSAKAWA, B. (1976) Thunder in the Rockies, New York: Morrow.

DIAZ RANGEL, E. (1974). Pueblos subinformados. Venezuela: Cuadernos de nuestro tiempo.

DÍAZ, R. (2008) "Unidos los unos con los otros" El gremio de los telegrafistas en Costa Rica (1880-1930)" En:. Inter.c.a.mbio, año 5, no. 6, Costa Rica:181-200.

EMERY, E. (1966). The press and America: an interpretative history of Journallism. United State: Englewood Cliffs.

FRASER, R. WBF- A. Typical Ute. Disponible desde Internet en: http://donmoore. tripod.com/genbroad/utes/wbf.htm

LOZANO, A. (2011) Breve historia de la Primera Guerra Mundial. España: Ediciones Nowtilus.

MICHAL, B. (1969). Los grandes enigmas de la gran guerra. Serie. Los grandes enigmas históricos de nuestro tiempo: Madrid.

MONTALVÁN, M. (1980). Historia y comunicación Social Barcelona: Bruguera.

MUNRO, D. (2003). Las cinco repúblicas de Centroamérica. San José: Editorial de la Universidad de Costa Rica.

SCHULZE, I. (1999). La propaganda alemana en la Segunda República Española. En: Historia y Comunicación Social, no. 4, Madrid: p.183-197.

STRACHAN, H. (2004). La Primera Guerra Mundial. Barcelona: Crítica.

Transocean. Disponible desde Internet en: http://www.archive.org/stream/investigationofu194102unit/investigationofu194102unit_djvu.txt

TULCHIN, J., (1971).The aftermath of War. World War I and U.S. Policy Toward Latin America. New York: New York University Press.

VEGA, P. (2007). "Primicias de la Primera Guerra Mundial en la prensa costarricense (1914)". En: Revista Intercambio. No. 4-5. 271-308. 
-- (2009). ¿Especulación desinformativa? (La Primera Guerra Mundial en los periódicos de Costa Rica y El Salvador). En: Revista Mesoamérica 51 (enero-diciembre) pp. 94-122.

-- (2010): La Primera Guerra Mundial desde el prisma de la prensa. La guerra en los periódicos de Centroamérica y Canarias. En: Memoria. Primer Congreso de Historia del Periodismo Canario: El periodismo y la cohesión territorial del Archipiélago. España: Universidad de La Laguna.

WAGNER, R. (1991). Los alemanes en Guatemala. (1828-1944). Guatemala: Editorial Idea.

WELL, G. (1994). El periódico. España: UTHEA.

\section{La autora}

Patricia Vega Jiménez es Doctora en Historia y Licenciada en Ciencias de la Comunicación Colectiva. Sus libros y artículos académicos tratan sobre historia de la comunicación en Centroamérica, historia del consumo y de la publicidad y el mercado laboral de los comunicadores sociales. Profesora y conferenciante en universidades de América Latina y Europa. Ha sido directora de la Escuela de Ciencias de la Comunicación Colectiva, del Programa de Posgrado en Comunicación, Vicedecana de la Facultad de Ciencias Sociales y actualmente es directora del Centro de Investigación en Comunicación, todos de la Universidad de Costa Rica. 